\title{
EDUCADORES DO CAMPO E MOVIMENTOS SOCIAIS EM FORMAÇÃO: EMBATES POLÍTICOS EM DEFESA DAS ESCOLAS DO CAMPO NO NOROESTE FLUMINENSE
}

\author{
RURAL TEACHERS AND SOCIAL MOVEMENTS UNDER \\ FORMATION: POLITICAL STRUGGLES FOR RURAL \\ SCHOOLS IN NORTHWESTERN RIO DE JANEIRO STATE
}

\author{
Francisca Marli Rodrigues de Andrade* \\ Lucas do Couto Neves**
}

\begin{abstract}
RESUMO: Fechar escolas do campo é um cenário que tem se consolidado em muitos Estados do Brasil, impondo às comunidades campesinas o apagamento do campo como lugar de reprodução da vida e de existência. No Noroeste Fluminense, as escolas do campo seguem a mesma trajetória de outras realidades brasileiras; ou seja, vítimas das práticas de fechamento, enquanto injustiças arquitetadas em argumentos economicistas. Porém, com a implementação da Licenciatura Interdisciplinar em Educação do Campo (LEdoC) da Universidade Federal Fluminense (UFF) na cidade de Santo Antônio de Pádua - Rio de Janeiro - uma série de movimentos populares confrontam a realidade de esvaziamento do campo. Nesse sentido, este artigo, com enfoque metodológico da pesquisa-ação, tem como objetivo descrever o caminho que estudantes da LEdoC da UFF e a comunidade de Santo Antônio de Pádua construíram, no âmbito da Pedagogia da Alternância, em defesa das escolas do campo, no período de 2015 a 2019. Os principais resultados destacam a importância da pesquisa-ação no fortalecimento das demandas locais e no processo de denúncia da retirada de direitos educativos das populações do campo. Ademais, os resultados sinalizam que os movimentos sociais populares fortalecem a formação de educadores do campo como política pública de reparação e de questionamento das situações de opressão, dentro e fora das instituições educativas.
\end{abstract}

Palavras-chave: Educação do Campo; Fechamento de Escolas; Formação de Educadores do Campo; Movimentos sociais.

ABSTRACT: Closing rural schools is a scene that has become usual in many Brazilian states, a fact that forces rural communities to quit life in the country as the place for both living and existence reproduction. Rural schools in Northwestern Rio de Janeiro State take the same path of other Brazilian realities; in other words, they are the victims of activity canceling, which is an injustice supported by economic arguments. However, the

\footnotetext{
" Doutora em Educação, Cultura da Sustentabilidade e Desenvolvimento pela Universidade de Santiago de Compostela (Espanha). Docente da Universidade Federal Fluminense (UFF). Contato: marli_andrade@id.uff.br

** Mestrando pelo Programa de Pós-Graduação em Meio Ambiente e Desenvolvimento Rural da Universidade Brasília (UnB). Contato: lucasdocouto@yahoo.com.br
} 
implementation of the course named Interdisciplinary Major Degree in Rural Education, also known as LEdoC, at Fluminense Federal University (UFF), in Santo Antônio de Pádua City, RJ, opened room for a whole series of popular movements to cope with the rural exodus reality. Accordingly, the aim of the present study is to describe the path opened between 2015 and 2019 by UFF's LEdoC and Santo Antônio de Pádua's community for the Alternation Pedagogy in order to defend rural schools, based on the research-action methodology. The main results have highlighted the importance of the research-action methodology to reinforce the local demands and the process of reporting the alienation of rural populations from their right to education. Moreover, they have pointed towards the fact that popular social movements reinforce rural teachers' formation by repairing public policies to question oppression situations in and outside education institutions.

Keywords: Rural Education; Schools' closing; Countryside teachers' training; Social movements.

\section{OS SENTIDOS DA LUTA EM DEFESA DAS ESCOLAS DO CAMPO}

A Educação escolarizada no Brasil, principalmente no meio rural, se expressa por diferentes aspectos colonizadores, hegemônicos e opressores, ferindo as culturas e os modos de produção da vida no campo. Nessa opressão, Ribeiro (2013) enfatiza que a concepção moderna de educação ainda carrega traços que nos imprime a história dos vencedores; ou seja, da classe burguesa 'vitoriosa' na transformação do feudalismo para o capitalismo. Tais histórias são apresentadas como verdades absolutas e irredutíveis, negando e subordinando aprendizados da experiência, da cultura e do trabalho. Enraizados na colonialidade do poder, do saber e do ser, as concepções que organizaram/organizam 0 pensamento educacional brasileiro estão "visceralmente atreladas às relações políticas e as formas específicas de pensar e conformar os coletivos sócio-étnico-raciais, de gênero, dos campos e periferias desde a empreitada colonial e continuando no ideário republicano" (ARROYO, 2014, p. 61).

Diante dessas relações coloniais presentes nos currículos escolares como ferramenta de dominação, os movimentos sociais populares pressionaram/pressionam o Estado brasileiro a repensar os modelos de educação que lhes são oferecidos, já que compreendem que "as concepções e práticas educativas pensadas para educá-los, civilizá-los estão condicionadas pelas formas de pensá-los, ou pelo padrão de poder/saber de como foram 
pensados para serem subalternizados" (ARROYO, 2014, p. 11). Na busca pela superação desses processos de subalternização, os movimentos sociais do campo - com destaque ao $\mathrm{MST}^{1}$ - têm tensionado o campo político por outro modelo de sociedade incluindo em suas lutas por terra e trabalho a crítica à realidade educacional opressora, particularmente à situação educacional do povo brasileiro que trabalha e vive no/do campo (CALDART, 2009). Esses movimentos assumiram o "desafio de conceber e desenvolver uma formação contra-hegemônica, ou seja, de formular e executar um projeto de educação integrado a um projeto político de transformação social liderado pela classe trabalhadora" (MOLINA; SÁ, 2012, p. 327).

No âmbito normativo, a proposta da Educação do Campo foi implementada por meio do Decreto no 7.352, de 4 de novembro de 2010, que dispõe sobre a política de Educação do Campo e o Programa Nacional de Educação na Reforma Agrária - PRONERA. Nessa implementação os movimentos sociais pensaram a dimensão educativa do trabalho e da vida no campo, em função da "relação que o trabalhador estabelece com a natureza, mediada pelas relações consigo mesmo e com outros trabalhadores, humaniza enquanto produz bens materiais, imateriais, linguagens, arte, conhecimento e cultura" (RIBEIRO, 2013, p. 44). Contudo, após uma década de implementação do Decreto 7.352/2010, o que se observa é a continuidade de um projeto econômico de esvaziamento do campo em todo o território nacional. Como afirma Schmitz e Castanha (2017, p. 46), "historicamente se naturalizou que a zona rural é um local de atraso, onde a escolarização não é importante. Atualmente, isso é percebido pela quantidade de escolas que estão sendo fechadas".

O projeto de esvaziamento do campo a partir da concepção de lugar atrasado é viabilizado, como assinala Arroyo (2014, p. 11), por meio de "concepções, epistemológicas de educação trazidas de fora, do centro civilizado e civilizador, [...] gestadas na concretude do padrão de poder/saber colonizador".

\footnotetext{
1 O MST - Movimentos dos Trabalhadores Rurais Sem Terra - tem liderado os movimentos sociais populares do campo desde 1990 na inclusão da educação como uma de suas primeiras demandas e, por isso, é visto "como o movimento mais fortemente organizado em quase todos os Estados do Brasil" (RIBEIRO, 2014, p. 35).
} 
Enquanto tentativa de resistência às concepções urbanocêntricas, o projeto político da Educação do Campo tem provocado tensões epistemológicas e políticas nas lutas em defesa dos direitos educativos das populações do campo. Nos últimos anos, tais lutas estão sendo articuladas para defender a continuidade do funcionamento das escolas do campo, uma vez que os movimentos sociais entendem que o ponto de partida para a transformação da escola deve ser a escola existente (CALDART, 2010). Sem escolas do campo não é possível construir Educação do Campo contra-hegemônica e, como consequência, torna-se mais difícil fortalecer os movimentos sociais de resistência que lutam contra a violação dos direitos fundamentais das populações do campo.

No Noroeste Fluminense - Rio de Janeiro - a presença da Licenciatura Interdisciplinar em Educação do Campo (LEdoC), da Universidade Federal Fluminense (UFF), está redesenhando as práticas de formação de educadores, na luta pela permanência das escolas do campo. Igualmente as demais LEdoC's de outras instituições - cuja identidade educacional também está ancorada na Pedagogia da Alternância - alimentam a "dialética entre a transformação das circunstâncias e a autotransformação que esse processo provoca e exige (acontece na práxis)" (CALDART, 2010, p. 65). Comprometida com as lutas sociais e com os direitos educativos, a comunidade acadêmica do curso, em colaboração com outros atores sociais, tem fomentado tensões políticas na região, em defesa das escolas do campo. Nesse sentido, o principal objetivo desta pesquisa se traduz na descrição, a partir de uma abordagem interpretativa, da nossa participação nos movimentos sociais populares, lutas e resistências pela manutenção das escolas do campo na cidade de Santo Antônio de Pádua - RJ, no período de 2015 a 2019.

\section{PEDAGOGIA DA ALTERNÂNCIA EM DIÁLOGO COM A PESQUISA-AÇÃO: MOVIMENTOS SOCIAIS EM FORMAÇÃO}

No Noroeste Fluminense, não diferente das demais regiões do país, as investidas do Estado para o fechamento de escolas do campo são pautadas em discursos economicistas, produzem a precarização e a usam como justificativa 
(SCHMITZ; CASTANHA, 2017; RODRIGUES, 2019). Como ressalta Rodrigues (2019, p. 30), "a precariedade da infraestrutura das escolas do campo decorre da ineficiência e descaso, intencional, do poder público em garantir a efetividade da política de Educação do Campo". Para confrontar esse descaso, diferentes atores se unem em um movimento decolonial de resistência e (re)afirmação de sua cidadania, reivindicando os direitos que the são básicos garantidos pela Constituição. Em defesa das escolas do campo, esses atores se asseguram na Lei $n^{\circ} 12.960$, de 27 de março de 2014, enquanto tentativa para impedir o fechamento de escolas do campo, indígenas e quilombolas antes da "análise do diagnóstico do impacto da ação e a manifestação da comunidade escolar" (BRASIL, 2014).

Inserindo-se no contexto de luta contra o fechamento de escolas do campo, o curso de Licenciatura Interdisciplinar em Educação do Campo, ofertado no Instituto do Noroeste Fluminense de Educação Superior (INFES) da Universidade Federal Fluminense (UFF), tem assumido papel fundamental na formação dos movimentos sociais de resistência. Diante de sua posição institucional em formar educadores para atuarem nas escolas do campo, esse curso tem articulado as lutas locais e está construindo um ambiente educativo que se fortalece em movimentos sociais em defesa das escolas. Logo, esse ambiente pensa "a totalidade pedagógica que é o movimento, sendo então capaz de fazer cada pessoa sujeito de um processo pedagógico especificamente voltado para sua formação" (CALDART, 2004, p. 400). Para além do ato de cidadania que é lutar pela manutenção das escolas do campo ativas, esse movimento está fortalecendo o curso e seus educandos enquanto participantes das diversas ações pedagógicas que surgem na prática social dos movimentos de resistência.

É, portanto, de dentro dos movimentos sociais populares, precisamente da organização das lutas sociais e de resistência contra o fechamento de escolas nas comunidades rurais de Santo Antônio de Pádua - Estado do Rio de Janeiro - que buscamos descrever nossas experiências forjadas no âmbito da Pedagogia da Alternância. Nessa descrição, com abordagem interpretativa, entendemos que "cada pesquisador constrói e reconstrói o problema de 
pesquisa tecido pelas suas vivências e percepções sociais, históricas, culturais e, principalmente, epistemológicas, que é o que possibilita reconhecer a existência de um problema de pesquisa" (ROSSATO; MARTÍNEZ, 2017, p. 344). Desse modo, este estudo, construído com orientação metodológica da pesquisaação, coloca em destaque que "ao longo da ação, e com a participação dos atores e dos investigadores, são captados os problemas e testadas as soluções" (COSTA, 1991, p. 51). Tal teste é viabilizado por meio da aplicação da intencionalidade política, razão pela qual o foco desta pesquisa é denunciar para transformar a realidade por meio do agir e do refletir; ou seja, "no sentido de aliar conhecimento e mudança" (DEMO, 1995, p. 231).

A opção pela abordagem metodológica da pesquisa-ação tem como argumento a ideia de que "quanto mais se problematizam os educandos, como seres no mundo e com o mundo, tanto mais se sentirão desafiados. Tão mais desafiados, quanto mais obrigados a responder ao desafio. Desafiados, compreendem o desafio na própria ação de captá-lo" (FREIRE, 2005, p. 80). Nessa perspectiva, a produção de conhecimentos age concomitantemente às "lutas de grupos subalternos pela emergência do saber ignorado e minimizado pelas ideologias hegemônicas" (COSTA, 1991, p. 50). Na organização dessa luta, como sinalizou Andrade e colaboradores (2019b), a Licenciatura Interdisciplinar em Educação do Campo se destaca por sua política-pedagógica, propiciando a elaboração da pesquisa-ação por meio da Pedagogia da Alternância.

Dividida entre dois espaços/tempos distintos, Tempo Universidade (TU) e Tempo Comunidade (TC), a Pedagogia da Alternância usa a dialética teóricoprática na construção de uma práxis autêntica e revolucionária, rompendo com a lógica dicotômica da colonialidade que "opera por separações sucessivas e reducionismos vários" (PORTO-GONÇALVES, 2005, p. 3). Promove assim, a autorreflexão de estudantes e da comunidade que "levará ao aprofundamento consequente de sua tomada de consciência e de que resultará sua inserção na História, não mais como espectadoras, mas como figurantes e autoras" (FREIRE, 1967, p. 36). Com esses elementos, o TC na Universidade Federal Fluminense (UFF), na cidade de Santo Antônio de Pádua - RJ, como sinalizou 
Andrade e colaboradores (2019a), funciona como um laboratório de experiências sociais. Na idealização dessas práticas e para além delas, podemos apontar três momentos que serviram de base de sustentação para a construção dessa proposta de estudo, pensado desde a pesquisa-ação:

$\checkmark$ Aprofundamento em conceitos, processos históricos e políticos da Educação do Campo, realizados durante debates e discussões em disciplinas no TU.

$\checkmark$ Estudos e entendimentos da realidade do campo no município a partir das reflexões dos conceitos aprofundados, principalmente, durante: TC; estágios e trabalhos nas escolas relacionados às disciplinas cursadas; vivências cotidianas de discentes que residem no território paduano.

$\checkmark$ Construção de ações conjuntas com diferentes atores sociais em movimentos em defesa das escolas do campo, realizados de acordo com as possibilidades de ação naquele momento.

Desta forma, esse estudo tem como objetivo não apenas produzir conhecimento, mas também assume um compromisso ético e político com a transformação da realidade (COSTA, 1991). No movimento de disputas fomentado pela Educação do Campo, "a luta concreta dá-se na e pela construção de relações sociais firmadas na cooperação e solidariedade" (FRIGOTTO et al., 2020, p. 14). Cooperação essa que se consolida entre as diferentes pessoas que protagonizaram a pesquisa: a) populações campesinas paduanas, com destaque especial para comunidade rural do Salgueiro; b) docentes, estudantes e coordenação da LEdoC da UFF e demais segmentos da comunidade acadêmica do INFES/UFF; c) professoras e professores da rede municipal de educação e outros servidores públicos da rede municipal. Essas pessoas foram não somente protagonistas de uma realidade que começa a ser transformada; mas, também, as/os produtoras/es dos principais dados que compõem esta pesquisa.

Construídos dialeticamente, a colaboração e cooperação desse coletivo conforme detalhado anteriormente - documenta uma história presente 
fortalecida nos movimentos de afirmação do campo como lugar de existência e resistência, contribuindo com uma formação comprometida com a defesa dos direitos humanos, com os princípios democráticos e com a justiça social. Nesse processo de documentação realizamos as seguintes atividades: a) entrevistas e documentários $^{2}$ - protagonizados pela comunidade do Salgueiro, lideranças locais e políticas; b) diários de campo; c) rodas de conversa; d) trabalhos de disciplinas específicas e de conclusão de curso; e) pesquisas em sites oficiais do MEC, nos documentos normativos nacionais e nas leis municipais. Todos esses instrumentos fazem parte da construção da nossa pesquisa, assim como a prática vivida nas diversas experiências construídas nas lutas de resistência. Nossa participação, enquanto comunidade acadêmica da LEdoC da UFF nos movimentos de resistência, foi iniciada na medida em que a realidade é problematizada; ou seja, a partir da consciência coletiva dos processos de injustiças e a negação de direitos básicos.

\section{EDUCAÇÃO DO CAMPO COMO FORÇA-POLÍTICA: ORGANIZAÇÃO E ATUAÇẢO DOS MOVIMENTOS DE RESISTÊNCIA}

No centro da discussão sobre Educação do Campo, em todos os níveis de escolarização, a Pedagogia da Alternância protagoniza o debate sobre uma política pedagógica que (re)afirma a identidade coletiva dos sujeitos e suas lutas nos processos de ensino/aprendizagem. A Pedagogia da Alternância - como foi destacada na proposta de regulamentação elaborada pelo Conselho Nacional de Educação (CNE) - busca a "interação entre o estudante e a realidade que ele vivencia em seu cotidiano, de forma a promover permanente troca de conhecimentos entre seu ambiente de vida e trabalho e a escola" (CNE, 2020). A interação que ocorre nessa troca sinaliza que não existe uma maneira única de fazer a dinâmica da Alternância, já que ela se dá na especificidade de cada realidade, cada contexto, cada localidade, em seus espaços e tempos pensados

\footnotetext{
2 Dois documentários foram produzidos no âmbito do Tempo Comunidade. As falas retiradas desses documentários serão codificadas para manter o sigilo dos participantes: DOC1 para as falas retiradas do primeiro documentário - Memória Social e Resistência: organização comunitária contra o fechamento da escola Alice do Amaral Peixoto; DOC2 para o segundo documentário - Memória e resistência: estrutura educacional do Noroeste Fluminense.
} 
como espaços/tempos. Diante disso, a concepção de educação como direito de todos afirma-se na construção de que o "povo tem direito a uma educação pensada desde o seu lugar e com a sua participação, vinculada à sua cultura e às suas necessidades humanas e sociais" (CALDART, 2002, p. 18).

Os marcos normativos da Educação do Campo destacam a Pedagogia da Alternância como "instrumentos pedagógicos que integram o conhecimento prático, o conhecimento científico, as diversas epistemologias coexistentes no mundo, as identidades e as territorialidades dos sujeitos, no âmbito da escola e de outras instituições educacionais" (CNE, 2020). Na experiência da LEdoC da UFF a Pedagogia da Alternância tem se concretizado a partir da denúncia da realidade local, na medida em que desestabiliza a lógica colonial do conhecimento que "vem agindo como um dos campos de segregação dos coletivos sociais, étnicos, raciais, de gênero não apenas por negar o caso, mas por não reconhecê-los capazes de conhecimentos verdadeiros" (ARROYO, 2014, p. 214). Integrando TU ao TC, a produção do conhecimento não acontece separada das lutas por direitos, do reconhecimento enquanto sujeitos coletivos de direitos e, principalmente, como produtores de conhecimentos subjugados à lógica colonial, racista e eurocentrada. Em movimentos contra-hegemônicos, a Pedagogia da Alternância na UFF se afirma na construção de temas transversais e interdisciplinares que se complementam na pluralidade das demandas emergentes, as quais serão detalhas a seguir.

\section{PEDAGOGIA DA ALTERNÂNCIA (RE)DESCOBRINDO E (RE)DESENHANDO LUTAS SOCIAIS PELO DIREITO Ȧ EDUCAÇÃO}

A implementação da LEdoC da UFF apresenta-se como um elemento fundamental na construção do debate que envolve a Pedagogia da Alternância e a organização das lutas sociais no município de Santo Antônio de Pádua - RJ. A implementação do curso - no ano de 2015 - aconteceu como resultado do edital $n^{\circ}$ 02/2012 do MEC que possibilitou a disposição de três vagas para técnicos, quinze vagas para docentes e uma verba específica para manutenção dos primeiros anos do curso. Uma vez implementado na Universidade Federal Fluminense (UFF), o curso se afirma enquanto única graduação da instituição 
que tem a Pedagogia de Alternância como elemento estruturante no seu projeto político-pedagógico. Em outras palavras, sua estrutura curricular coloca em diálogo dois espaços/tempos distintos de aprendizagem - Tempo Universidade (TU) e Tempo Comunidade (TC). Ambos tecem relações entre as diversas epistemes dos educandos e das suas comunidades com os conhecimentos construídos a partir da perspectiva científica. Uma série de outras políticas públicas e eventos, fruto das mobilizações dos movimentos sociais populares do campo, também foram fundamentais para a concepção da Educação do Campo e a definição de escolas do campo. Entre elas Bicalho (2018, p. 29) enfatizou:

a) Constituição da República Federativa do Brasil de 1988, Título I, Artigo 3ํ., IV; e Capítulo III, Seção I, Art. 206; b) Lei de Diretrizes e Bases da Educação Nacional (LDB) n. 9.394/96, Art. 28, 78, 79; c) Encontro Nacional de Educadores da Reforma Agrária (ENERA), organizado em 1997 pelos movimentos sociais do campo, em parceria com a Universidade de Brasília (UnB); d) Programa Nacional de Educação na Reforma Agrária (PRONERA), criado em 1998, junto ao Instituto Nacional de Colonização e Reforma Agrária (INCRA), atualmente no Ministério do Desenvolvimento Agrário (MDA); e) Resolução n. 1 do Conselho Nacional de Educação (CNE)/ Câmara de Educação Básica (CEB), de 3 de abril de 2002, Diretrizes Operacionais para a Educação Básica das Escolas do Campo; f) Programa Escola Ativa; g) ProJovem Campo - Saberes da Terra; e) ProJovem Rural; f) Programa de Apoio à Formação Superior em Licenciatura em Educação do Campo (PROCAMPO), criado em 2007, tem por finalidade formar educadores por área de conhecimento, via pedagogia da alternância, para atuarem junto às escolas do campo; g) Lei $\mathrm{n}$. 11.947, de 16 de junho de 2009, dispõe sobre o atendimento da alimentação escolar e do Programa Dinheiro Direto na Escola aos alunos da educação básica; h) Resolução n. 4, de 13 de julho de 2010, que define as Diretrizes Curriculares Nacionais Gerais para Educação Básica, e nela, a educação do campo, como modalidade de ensino; i) Decreto n. 7.352, de 4 de novembro de 2010, que dispõe sobre a Política de Educação do Campo e o Programa Nacional de Educação na Reforma Agrária (PRONERA); j) Programa Nacional de Educação do Campo (PRONACAMPO), de 20 de março de 2012; k) Fórum Nacional de Educação do Campo (FONEC); I) Portaria n. 391, de 10 de maio de 2016, que estabelece orientações e diretrizes aos órgãos normativos dos sistemas de ensino para o fechamento de escolas do campo, indígenas e quilombolas.

A partir desses eventos e políticas, a implementação do curso de Educação do Campo em Santo Antônio de Pádua - RJ, traz consigo a concepção de Educação do Campo como um movimento da classe popular do campo, intensificando a "pressão por políticas públicas que garantam o acesso cada vez mais ampliado dos camponeses, do conjunto dos trabalhadores do 
campo, à educação" (CALDART, 2009, p. 60). Um movimento que tem alimentado as lutas de resistência em defesa das escolas do campo, ao mesmo tempo em que questiona sua atual função e pensa sua transformação; ou seja, a busca por uma escola que trabalha "os interesses, a política, a cultura e a economia dos diversos grupos de trabalhadores e trabalhadoras do campo, [...] produzindo valores, conhecimento e tecnologia na perspectiva do desenvolvimento social e econômico igualitário desta população" (ARROYO, 2004, p. 53). Essas concepções são as bases da Pedagogia da Alternância na organização das lutas sociais locais em defesa da Educação do Campo que, sistematizadas no mapa a seguir, detalha o percurso que seguiremos desde a implementação do curso até as principais atividades objeto de análise nesta pesquisa. 
Figura 1 - Sistematização dos elementos fundamentais na construção do movimento social em defesa da Educação do Campo no Noroeste Fluminense - RJ

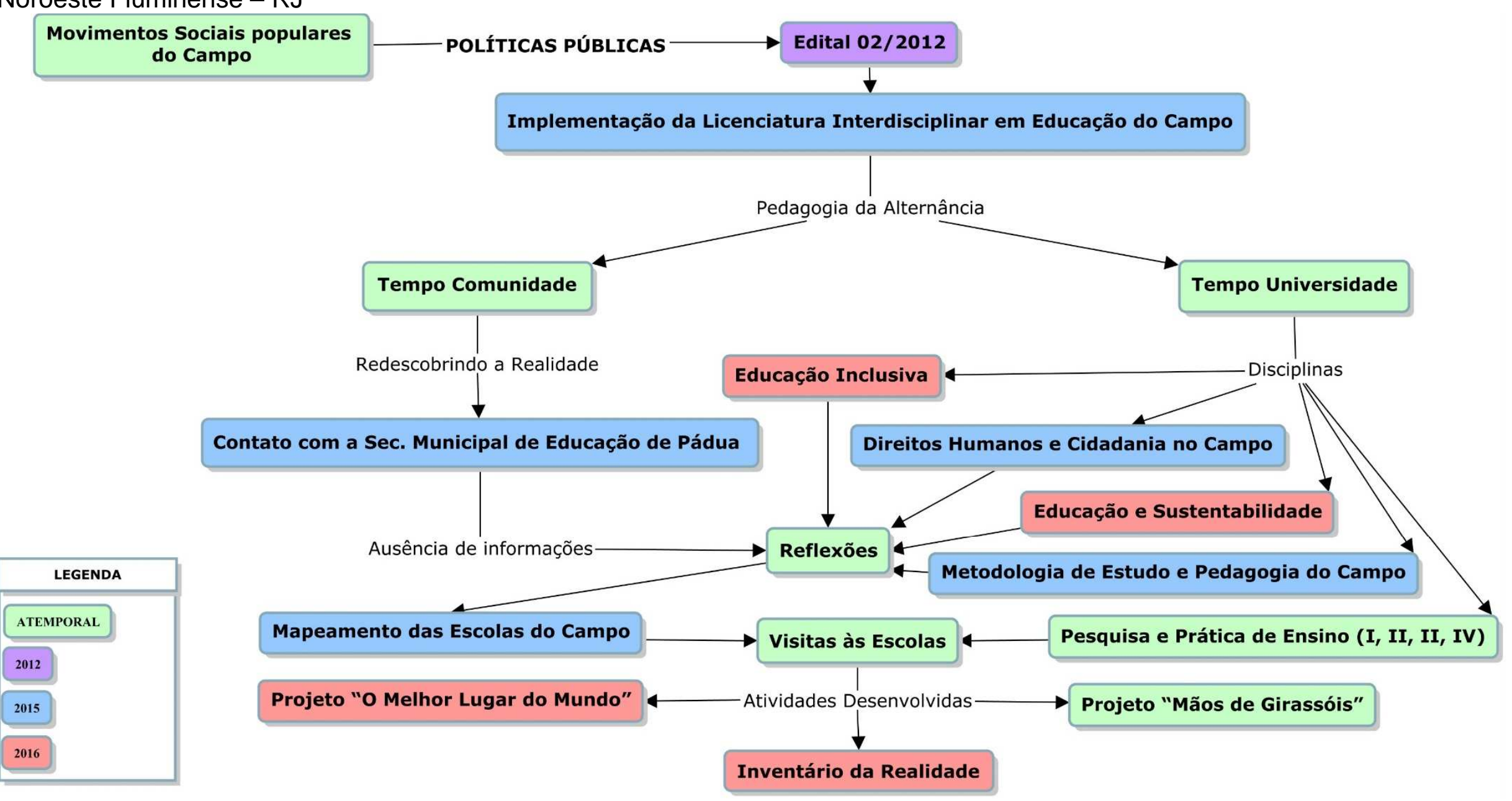

Fonte: Elaboração nossa. Dados da pesquisa (2015 - 2018). 
De acordo com a Figura 1, após a implementação da LEdoC da UFF a Pedagogia da Alternância tem guiado o caminho que nos inseriu na organização e na luta em defesa da Educação do Campo na região do Noroeste Fluminense. Inserindo na política institucional da universidade dois espaços/tempos de aprendizagem que se entrelaçam e dialogam na construção de uma práxis revolucionária - Tempo Universidade (TU) e Tempo Comunidade (TC) - foi possível destacar a força política da Pedagogia da Alternância. Tal força, conforme identificado em outras pesquisas, propõe respostas "contrahegemônicas à colonialidade do saber, demarca o campo teóricometodológico e epistemológico da Educação do Campo, desde outras leituras e compreensões do mundo e da realidade" (ANDRADRE et al, 2019a, p. 14). Assim, o TU e o TC aproximam a pluralidade de conhecimentos na tentativa de "construir puentes de convergencia entre proyectos intelectuales, entre comunidades interpretativas y entre las disciplinas que estudian lo social-cultural, y también entre éstas y los saberes locales" (WALSH, 2013, p. 14).

No TU, o aprofundamento de conceitos relacionados às escolas do campo tem nos permitido compreender a realidade política e epistêmica, denunciando as injustiças que nos cercam. No TC, a força política da Alternância tem nos possibilitado (re)descobrir a realidade de injustiças e confrontá-las. A partir do enfoque da pesquisa-ação, iniciamos a organização dos movimentos sociais em defesa das escolas do campo. O (re)descobrir a realidade - processo que aconteceu na problematização das questões escolares municipais - iniciou-se com o contato entre nós, comunidade acadêmica do curso e membros das comunidades rurais, com a Secretaria Municipal de Educação de Pádua - RJ. Esse encontro foi planejado durante o TC do segundo semestre de 2015, a partir de problematizações criadas no TU, com o objetivo de entender a situação das escolas do campo no município. Na ausência/negação de informações nesse primeiro contato, a principal reflexão dessa etapa da pesquisa-ação girou em torno da construção desses dados, movimento que seguiu com o mapeamento e visitas às escolas do campo do município, realizados durante as diversas vivências construídas em ambos os espaços/tempos. 
Nos momentos iniciais dessa pesquisa, nossas hipóteses foram pautadas no descaso intencional, por parte do Estado, com as escolas do campo. A configuração desse descaso, o que posteriormente foi analisado com mais cuidado nas pesquisas de Andrade e Rodrigues (2020), sinaliza que o poder público formulava/formula desculpas orçamentárias na tentativa de esvaziamento do campo a partir do sucateamento das escolas nas zonas rurais. No âmbito do trabalho empírico, imersos nessa realidade local, a percepção inicial se reafirma. Pois, na medida em que nos aproximávamos da realidade de cada comunidade e de cada escola em ambos os espaços/tempos da Alternância - TU e TC - ficava mais evidente que a questão não é de fato orçamentária, mas sim política.

No TC, uma das pesquisas que realizamos, mapeamento das escolas do campo, buscou elaborar um registro das escolas caracterizadas como do campo e as não caracterizadas como do campo, mas localizadas em distritos e que atendiam estudantes das zonas rurais. Durante este levantamento, foi possível dialogar com as escolas conhecendo suas dificuldades e enfrentamentos, assim como desenvolver atividades em parcerias. Na realização dessas parcerias, pensadas desde a pesquisa-ação no âmbito do TU, tal como sinalizado por Andrade e Rodrigues (2020), ligavam disciplinas do curso de Educação do Campo às comunidades rurais locais, questionando as realidades de injustiça e descaso com essas populações. Da nossa percepção no processo de elaboração desse estudo, entre as principais disciplinas que iniciaram ações no município, podemos destacar: Educação Inclusiva; Metodologia de Estudos e Pedagogia do Campo; Direitos Humanos e Cidadania no Campo; Educação e Sustentabilidade; Pesquisa e Prática de Ensino (I, II, III e IV). Nessas disciplinas desenvolvemos projetos concretos, dentre os quais podemos ressaltar: "Mãos de girassóis" e "O melhor lugar do mundo é aqui".

Durante as disciplinas e projetos citados, atividades como teatro, visitas pedagógicas, oficinas sobre sustentabilidade e agroecologia, rodas de conversa com a comunidade e até mesmo reformas foram feitas nas escolas do campo. Essas atividades, elaboradas em ambos os espaços/tempos possibilitaram a aproximação com os sujeitos do campo e o conhecimento das comunidades. 
Como resultado, construímos o Inventário da Realidade, atividade que surge da potência dialética que a Pedagogia da Alternância proporciona na horizontalidade entre comunidades-estudantes-docentes consolidada "na dialetização entre a denúncia da situação desumanizante e o anúncio de sua superação" (FREIRE, 2000, p. 81). Com o inventário da realidade, realizado na escola Alice do Amaral Peixoto, foi possível (re)descobrir a geografia do campo - social e epistêmica - a partir do detalhamento de informações que a princípio eram simples, mas que organizam características importantes no desvelar da realidade; isto é, sua localização e acesso, corpo docente e estudantil da escola, fontes de renda da região e dos estudantes, serviços de atendimento públicos, biodiversidade, etc.

Com a situação desvelada no inventário da realidade, a luta pela transformação começou a ser redesenhada mediante a força-política da Pedagogia da Alternância, a qual "pressupõe uma sinergia, uma integração e uma interpenetração que possibilite romper com a dicotomia teoria e prática, abstrato e concreto, conhecimentos escolares e saberes tradicionais, formação e produção, trabalho intelectual e trabalho manual” (CNE, 2020, p. 4). Desse modo, todas essas atividades apresentadas na Figura 1 procuravam melhorar a qualidade da educação dos "educandos que precisam aprender hoje e não ficar esperando pela solução dos problemas da escola" (CALDART, 2010, p. 69). Contudo, o movimento social que se iniciava era consciente de que essas atividades não eram suficientes para garantir a permanência das escolas abertas, algo que foi concretizado em seguida, conforme registrado na pesquisa de Rodrigues (2019). Assim, a escola Anacleto Eccard Junior foi fechada no final do ano letivo de 2016 e João Neves Brum foi fechada em julho de 2017; isto é, nem mesmo atividades pedagógicas sem recurso financeiro da prefeitura mantiveram as escolas abertas, evidenciando que o verdadeiro intuito do poder público era fechá-las.

Com a concretização do fechamento das duas escolas, o movimento social que estava em processo de organização entendeu que a única atividade que poderia manter as escolas abertas seria a luta coletiva que, por fim, também se assume como atividade pedagógica. No redescobrir dessa realidade, 
principalmente na descodificação da realidade a partir do aprofundamento em conceitos que a formação de educadores do campo evoca, foi possível compreender que a realidade é uma construção e que enquanto sujeitos históricos podemos transformá-la. Na associação entre teoria e prática, pensada desde a Alternância, ficou evidente que é na "inserção lúcida na realidade, na situação histórica, que a levou a crítica dessa mesma situação e ao ímpeto de transformá-la" (FREIRE, 2005, p. 61). Por isso, junto às comunidades locais, inserimo-nos - enquanto movimento social - como sujeitos históricos, questionadores de verdades e agentes da transformação. Pois, como enfatiza Arroyo (2014, p. 315), "conhecer com profundidade os complexos processos históricos de seu não reconhecimento ou da decretação de sua inexistência, inferioridade, sub-humanidade, subcidadania é uma precondição para pensar em políticas públicas".

A Pedagogia da Alternância, enquanto principal dispositivo contrahegemônico, consolida "o poder da ação-reflexão das práticas sociais nos territórios - geográficos e epistemológicos - da Educação do Campo desencadeiam ações de fortalecimento da cidadania e de organização das lutas sociais" (ANDRADE, et al, 2019a, p. 27). No caso deste estudo em concreto, em um diálogo intermitente entre a realidade do educando e sua construção teórica formativa, a Pedagogia da Alternância integra as lutas sociais por direito à educação ao processo curricular de ensino aprendizagem. Pois, comprometida com uma pedagogia contra-hegemônica, compreende que "las luchas sociales también son escenarios pedagógicos donde los participantes ejercen sus pedagogías de aprendizaje, desaprendizaje, reaprendizaje, reflexión y acción" (WALSH, 2013, p. 29). Na construção de cenários e de um quefazer político pedagógico, nos juntamos em diferentes vozes que ecoam em defesa do direito à educação, ao direito a ter direito. Essas vozes questionam, como sinaliza Arroyo (2014, p. 330) "os classificados como subcidadãos" e, ao mesmo tempo "põem na cena política formas de cidadania mais dinâmicas".

PEDAGOGIA DA ALTERNÂNCIA E ORGANIZAÇÃO DAS LUTAS SOCIAIS: TENSÕES POLÍTICAS NA CIDADE DE SANTO ANTÔNIO DE PÁDUA 
Os ataques contra a educação, principalmente contra a Educação do Campo, forjaram atores que se colocam em cena na defesa de direitos constitucionais. Como aponta Cunha (2001, p. 65), "o Estado, por sua omissão ou por suas políticas antidemocráticas tem sido o verdadeiro impulsionador dos movimentos sociais". Em denúncia ao fechamento das escolas Anacleto Eccard Junior e João Neves Brum, movidos pelo sentimento de indignação, os passos no asfalto quente do entardecer marcam o primeiro ato organizado, com a participação da LEdoC da UFF, no centro da cidade de Santo Antônio de Pádua - RJ. Afirmando-se (re)existentes, as populações do campo e o curso de Educação do Campo da UFF, entre outros segmentos e sujeitos presentes na coletividade, começam um movimento de resistência contra o apagamento do campo. Esse apagamento não acontece somente hoje, se faz presente por décadas no município, com o sistemático fechamento de escolas nas áreas rurais. 
Figura 2 - Sistematização do processo de organização social em defesa da Educação do Campo no Noroeste Fluminense - RJ

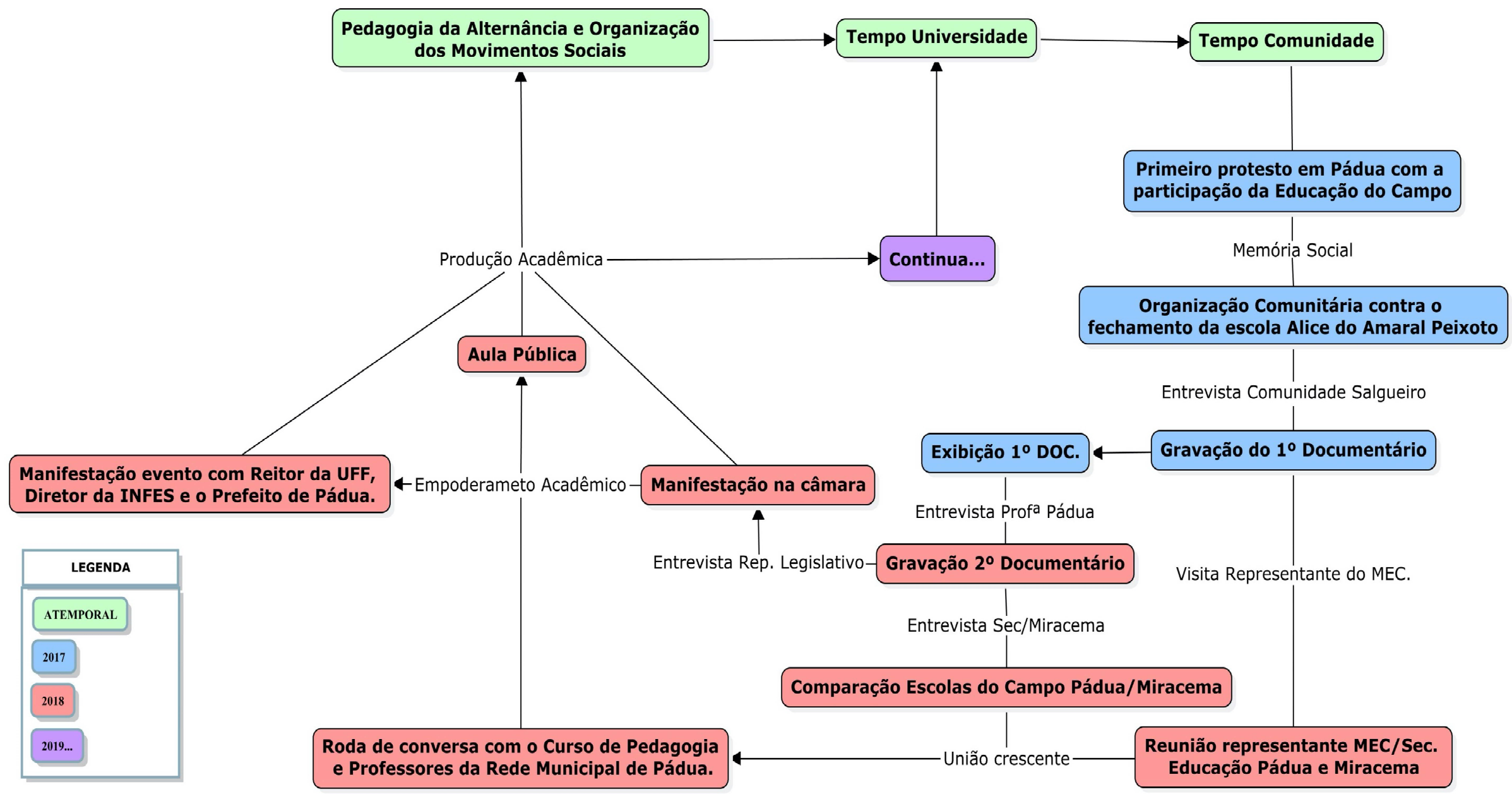

Fonte: Elaboração nossa. Dados da pesquisa (2015 - 2018). 
Diante do primeiro protesto contra o fechamento de escolas do campo com participação da LEdoC da UFF, percebemos que, conforme destacou Sader (1988, p. 32) "pequenos atos, que até então seriam considerados insignificantes ou reiteração de uma impotência, começam a receber novas conotações". Principalmente pelo encontro de sujeitos que começaram a construir a coletividade, pois, como apontou Marx e Engels (2020, p. 142), "o verdadeiro resultado de suas lutas não é o sucesso imediato, mas a união crescente". A partir da experiência da primeira organização social de denúncia contra 0 fechamento das escolas do campo, o poder público local se depara com outros movimentos que começam a ganhar força política e, assim, questionarem as antipolíticas do Estado. Como exemplo, as comunidades do Salgueiro e Arraialzinho, em coletividade com outros sujeitos em luta, consolidou o primeiro ato de resistência efetivo em defesa das escolas Alice do Amaral Peixoto e José Lavaquial Biosca. A mensagem que ficou desse movimento, como relatou uma moradora do bairro rural de Salgueiro no Primeiro Documentário,

É de que a gente nunca pode parar de lutar pelos nossos direitos, que a gente tem o direito de ter educação aqui no nosso bairro. É uma sensação de que valeu a pena lutar, a preocupação, a comunicação das pessoas em participarem da reunião, tudo valeu a pena (DOC1).

Entendendo a relevância desse acontecimento e toda potência desse ato de resistência, mas compreendendo também que a luta não acabaria com esse triunfo efêmero, elaboramos dois documentários, com a finalidade de registrar em áudio e vídeo - todo processo de resistência e luta que se mostrava fundamental para que a união da coletividade continuasse crescente. Amparados nas atividades do TC; ou seja, em sua "importância social, política e epistêmica, quando recoloca o estudante em sua própria comunidade, não apenas na condição de estudante, mas, também, como educador em potencial, fruto daquela realidade" (ANDRADE et al., 2019a, p. 27), começamos a construção do Primeiro Documentário. Tal documentário teve como título: Memória social e resistência: organização comunitária contra o fechamento da Escola Alice do Amaral Peixoto, proposto para guardar a memória social da luta coletiva. Como forma de articular mais atores na luta em defesa da Educação do 
Campo, assim como preservar e manter a memória desse fato histórico, nosso primeiro documentário foi gravado com os protagonistas desse movimento; ou seja, com a comunidade do Salgueiro.

Esse movimento adentrou na realidade educacional do município para, então, dialogar com diversos atores que permaneceram em coletividade nas lutas recentes. Como relata um morador no Primeiro Documentário, "a luta foi válida, mas talvez ela ainda não tenha terminado" (DOC1). Diante disso, todos nós sabíamos que era preciso manter a mobilização coletiva e, como estratégia, pensamos em um Segundo Documentário - Memória e resistência: estrutura educacional do Noroeste Fluminense, com uma liderança que se movimenta dentro da rede educacional do município. Nesse documentário destacamos o protagonismo de uma professora concursada. A proposta inicial do Segundo Documentário era estabelecer um diálogo sobre os bastidores do sistema educacional no município, desvelar sua realidade e pensar sua transformação. Dentre as diversas negligências, problemas de ordem salarial, material didático e estrutura escolar pautaram as principais falas. Em contrapartida, esse diálogo foi além dos limites territoriais de Santo Antônio de Pádua - que não paga o piso nacional dos professores - e pontuou o contraste com uma cidade vizinha. Como relata essa liderança (DOC2):

\begin{abstract}
A gente ganha um salário que não nos sustenta sob hipótese alguma e que é completamente diferente do salário dos nossos colegas aqui do lado de Miracema. É uma cidade menor, menor número de alunos, que o FUNDEB naturalmente vem equiparado, ou seja, uma contagem menor, e lá a gente recebe mais do que a gente recebe aqui.
\end{abstract}

Diante desse novo quadro, buscamos o diálogo com a Secretaria Municipal de Educação de Miracema, que aceitou nosso convite para fazer parte do segundo documentário. Em contraste com a educação do município de Pádua que fecha escolas do campo e segmentos, o município de Miracema está "com uma obra que supera $R \$ 50.000$, para uma escola que tem 17 alunos" (DOC2). Além do investimento na estrutura física das escolas, como forma de melhorar a educação e fortalecer a vontade dos estudantes em permanecerem na região, duas outras ações foram fundamentais: o funcionamento da escola em horário integral e o aumento de funcionários, principalmente professores dividindo as 
turmas de educação infantil das turmas de primeiro segmento (DOC2). Para comparar essas realidades, após as gravações do segundo documentário visitamos as escolas do campo fechadas em Pádua e as escolas que receberam investimento em Miracema. Cada vez mais imersos na realidade educacional do município de Pádua, ficou evidente que o fechamento de escolas do campo é um projeto que se estende em grande parte do Brasil. Como aponta Bicalho e Bezerra (2018, p. 102),

Nos últimos 15 anos, lidamos diariamente com o fechamento criminoso e aleatório das escolas do campo no Brasil. Segundo fontes do INCRA - Instituto Nacional de Colonização e Reforma Agrária; do PRONERA - Programa Nacional de Educação na Reforma Agrária; da UNESCO - Organização das Nações Unidas para a Educação, a Ciência e a Cultura; da UNESP - Universidade Estadual Paulista; do IPEA Instituto de Pesquisa Econômica Aplicada e do II PNERA - Relatório da II Pesquisa Nacional sobre Educação na Reforma Agrária, cerca de 32.512 escolas foram fechadas na última década.

Para confrontar esse projeto, pensamos na necessidade de fazer a exibição do primeiro documentário que foi realizado durante o TU no dia 21 de agosto de 2018, com a presença de alguns moradores que denunciaram as injustiças contra o campo no município. Essa exibição aconteceu no pátio do INFES/UFF, com o propósito de mobilizar para a luta dos movimentos de resistência, tanto os ingressantes do curso de Educação do Campo, quanto a comunidade acadêmica do INFES que transitava pelo pátio, introduzindo-Ihes na realidade da principal luta local. Uma luta que não demorou em ser, novamente, necessária. Dessa vez, contra o fechamento do segundo segmento do Ensino Fundamental - do $6^{\circ}$ ao $9^{\circ}$ ano - das escolas Antônio Teixeira Jardim e Professor José Pinto de Souza dos distritos de São Pedro e Marangatu - distritos rurais da cidade de Santo Antônio de Pádua - RJ. Em novos movimentos, nos juntamos a essas comunidades no ato de resistência que aconteceu com a Ocupação da Câmara de Vereadores - 26 de novembro de 2018, com cartazes que denunciavam o fechamento desses segmentos, pontuando que essa era uma atitude contra a vontade da população.

A organização do movimento, no âmbito da pesquisa-ação, teve certas aproximações àquilo que Andrade e Corrêa (2020, p. 123) destacaram enquanto vantagens dessa metodologia: a potência epistêmica de denúncia, uma vez que 
"os profissionais da área enquanto educadoras e educadores sociais podem tornar-se agentes de transformação dos espaços-temáticos”. Como ressaltou as autoras, a pesquisa-ação pode "reiterar pautas, fortalecer o engajamento comunitário e incentivar o protagonismo na luta por direitos sociais, políticos, econômicos e ambientais" (ADRADE; CORRÊA, 2020, p. 123). Esses elementos também foram observados na construção do movimento contra o fechamento das escolas do campo no Noroeste Fluminense. Na construção dessa mobilização entrevistamos, também, o único vereador que ficou em defesa da manutenção das escolas do campo, no que diz respeito à oferta do segundo segmento do Ensino Fundamental - do $6^{\circ}$ ao $9^{\circ}$ ano.

O Segundo Documentário reuniu três entrevistas com os seguintes colaboradores: a) Professora da Rede Municipal de Pádua; b) Secretário de Educação da cidade de Miracema; c) Vereador de Pádua. A realidade de luta, talvez tenha sido o maior protesto popular contra a violação, por parte do Estado, do direito à Educação do Campo na região do Noroeste Fluminense - resistiu por um ano. Contudo, as forças assimétricas não permitiram que o movimento acabasse com os ataques diários e com a precarização da educação nas áreas mais vulneráveis. Esses ataques se ampliaram e foram institucionalizados com o fechamento desse segundo segmento nas escolas, cujo poder local não considerou o direito constitucional da população. Tais fechamentos escancararam que a intenção da descaracterização das escolas distritais, como escolas do campo, é uma estratégia para driblar a Lei n 12.960/2014, que proíbe o fechamento de escolas do campo antes da análise dos impactos e a manifestação popular da comunidade afetada. Essa tem sido, como aponta Schmitz e Castanha (2017, p. 41),

\footnotetext{
A dura realidade enfrentada pelas escolas do campo, que mesmo com a mobilização dos movimentos sociais articulados com a sociedade, que pressionaram/pressionam para a criação de uma legislação que dificulte o fechamento de escolas, não se tem a garantia, na prática, de que escolas do campo não sejam fechadas.
}

No período de fechamento do segundo segmento do Ensino Fundamental nas escolas do campo, que se alongou por um ano de tentativas de desmobilizar os movimentos de resistência, tivemos a visita de um representante do Ministério 
da Educação (MEC). Essa visita teve como finalidade o levantamento de informações sobre a realidade em que se encontrava o processo de institucionalização da Licenciatura Interdisciplinar em Educação do Campo da UFF; bem como, entender a inserção do curso na comunidade local. Nessa perspectiva, concretizou-se uma reunião solicitada pelo representante do MEC com a participação das Secretarias Municipais de Educação das cidades de Pádua e Miracema, coordenação da LEdoC da UFF e representação estudantil do curso. A reunião abordou a principal pauta da comunidade acadêmica do curso: as explicações sobre as tentativas de fechamento, os fechamentos concretizados e a inserção educador do campo na agenda das secretarias da região.

Durante a reunião com o representante do MEC e da LEdoC da UFF, o poder público Municipal de Santo Antônio de Pádua foi questionado sobre o fechamento das escolas. Em resposta, alguns apontamentos não correspondiam com a realidade, principalmente a negação das tentativas de fechamento das escolas do campo. A verdadeira resposta, na contramão do discurso distorcido apresentado durante a reunião com o representante do MEC, veio no ano seguinte: o poder público fechou o segundo segmento do Ensino Fundamental - do $6^{\circ}$ ao $9^{\circ}$ ano - nas escolas dos distritos de Marangatu e São Pedro, e continuou com os ataques às escolas do campo de outros distritos e bairros rurais, entre elas a escola Alice do Amaral Peixoto. Nesta nova investida do poder público, notícias de um possível fechamento ruminavam nos corredores das escolas na tentativa de monitorar uma possível mobilização e, assim, agir a depender das circunstâncias.

Como forma de reação aos ataques diretos e rumores que aconteciam nos distritos e bairros rurais, uma roda de conversa realizada em conjunto com o curso de Pedagogia do INFES marcou a organização de dois atos de resistência: o primeiro ato foi uma manifestação realizada no auditório do INFES/UFF, durante evento que se encontravam o Reitor da UFF, o Diretor do INFES e o Prefeito do município de Santo Antônio de Pádua, na data de 11 de dezembro de 2018; o segundo ato foi uma aula pública com o tema "Educação do Campo e Direitos Humanos", ministrada por um docente da LEdoC da UFF, 
no dia 12 de dezembro de 2018. Esses movimentos asseguraram a continuidade da escola Alice do Amaral Peixoto, com o funcionamento das turmas de Educação Infantil e primeiro segmento do Ensino Fundamental - do $1^{\circ}$ ao $5^{\circ}$ ano.

Apesar das lutas, as ameaças de fechamento de escolas do campo continuam e seguem a mesma lógica de esvaziamento e precarização, pautadas nos discursos dos governos. Entre tais discursos, Andrade e Rodrigues (2020) destacam: baixo número de alunos, falta de recurso para reformas, alto custo de aluno se comparado ao ensino em área urbana, custo com transporte, etc. Diante da negação do direito à Educação do Campo, “o jovem não está mais ficando no campo, está partindo para a cidade em busca de estudo, e na maioria das vezes, não mais retorna, provocando o esvaziamento do campo" (SCHMITZ; CASTANHA, 2017, p. 41). Bicalho e Bezerra (2018, p. 102), acrescentam que "a ausência de escola ou o seu fechamento é fator decisivo para tal migração, somados ao caráter autoritário e conservador presente nas escolas do campo, em sua grande maioria, distante das especificidades camponesas". Em contrapartida, a Escola do Campo aberta, além da possibilidade de manter o jovem no campo, ajuda na construção de uma educação de qualidade a partir da própria realidade do educando, como representa a fala destacada do nosso segundo documentário:

Imagina uma escola que você pode falar de produção e materializar ela? A gente podia estar falando de produção, a gente podia estar falando de sustentabilidade, a gente podia estar falando de pesquisa dentro das escolas. A gente podia estar se alinhando a grupos de pesquisa, tanto universitários, como para além (DOC2).

Essa última fala representa um dos questionamentos críticos que a LEdoC da UFF, com base na Pedagogia da Alternância, provoca nos sujeitos, contribuindo com o espírito das lutas dos movimentos de resistência. Essas lutas têm diversas finalidades, como desconstruir a concepção de campo como lugar de atraso, pois afirma a materialidade dialética da realidade como pesquisa que, neste momento, se faz na reivindicação política pela manutenção das escolas do campo. A realidade ainda é de luta! Neste cenário, ver as escolas resistindo e os coletivos sociais se mobilizando na reivindicação pelo direito à Educação do Campo tem se tornado algo constante. Como expressa o depoimento obtido 
no segundo documentário, "foi logo depois desse movimento de vocês com os outros distritos, a gente meteu o pé também. Aliás, a gente agradece muito a UFF, se não fosse a UFF colaborar com a gente nesse processo, a gente não tinha conseguido" (Relato sobre a resistência da escola José Lavaquial Biosca no bairro Arraialzinho). É a partir dessa política pedagógica que estamos conseguindo a interação entre a comunidade acadêmica e as populações do campo da região, construindo resistências e fortalecendo a concepção de que o campo é lugar de saberes, lutas, epistemologias e, principalmente, de reprodução de vida, pois...

\footnotetext{
Quando lutam pela escola ou pela universidade defendem seu direito ao conhecimento, à ciência, às tecnologias, mas reagem contra um conhecimento que inferioriza seus conhecimentos, seus letramentos, seus saberes e culturas como imprecisões, misticismos, irracionalidades políticas (ARROYO, 2014, p. 225).
}

Como resposta a esse pensamento colonial que inferioriza o campo, a Pedagogia da Alternância está permitindo aberturas para que as demandas da comunidade local sejam levadas em consideração dentro e fora da universidade. À medida que os sujeitos do campo começam a ocupar a universidade e o meio acadêmico com questões pertinentes a sua realidade, questionam também a sua representação nesses espaços, afirmam-se existentes e questionadores de "verdades". Isto é, afirmam-se enquanto "sujeitos de seu próprio processo de formação para se construir como tal" (CALDART, 2009, p. 60), o que fortalece o debate e a mobilização das lutas sociais em defesa das escolas do campo; na mesma medida em que se afirmam enquanto produtores de conhecimentos. Nessa perspectiva, toda produção acadêmica da LEdoC da UFF, em colaboração com as comunidades do campo no Noroeste Fluminense, está sendo construída em defesa das escolas do campo no município e, desse modo, consolida nossa ocupação nos lugares de conhecimento. Da mesma forma, denuncia as injustiças e ausência de direitos fundamentais e, ao tempo, fortalece outros movimentos e lutas de superação.

\section{EDUCAÇÃO DO CAMPO EM MOVIMENTOS DE CONTINUIDADE...}


A proposta desta pesquisa-ação - no âmbito da Pedagogia da Alternância e para além dela - reúne uma sistematização do início de um movimento social que ainda está longe de acabar, que questiona a realidade e que conta com muitas atividades em andamento. Deixando sua marca no município, mostra que a cada ano a LEdoC da UFF está mais ativa nos movimentos de resistência e de luta em defesa das escolas do campo; bem como, de outras minorias políticas. Um aspecto que marca esse fortalecimento mútuo, pois ao passo que a comunidade entende a Educação do Campo como uma construção coletiva, comunidade-educandos-docentes, a luta toma proporções maiores e se afirma com o real potencial que esperamos. Em movimentos dialógicos, o curso tem potencializado as lutas sociais por sua inserção crítica na realidade dos educandos e sua consolidação dentro dos territórios em disputas. Imerso na realidade local, o curso é fortalecido na mesma medida em que fortalece os movimentos sociais.

Assume, assim, sua construção política, social e epistêmica forjada na classe popular camponesa, abrindo o meio acadêmico para outros saberes construídos na luta pela transformação da realidade da Educação do Campo no Noroeste Fluminense. Desse modo, coloca em pauta a reafirmação da importância do curso de Educação do Campo na luta pela sobrevivência das escolas do campo no município; bem como, a relevância desses movimentos para a afirmação do curso enquanto proposta de formar sujeitos para a transformação da sociedade. Por meio da Pedagogia da Alternância, o movimento social contra o fechamento das escolas do campo no Noroeste Fluminense está rompendo com a tradição colonial pedagógica que, historicamente, vem atuando para colocar as populações do campo à margem da construção da história; ou seja, como meros espectadores na atuação política. Nesse sentido, a proposta da Pedagogia da Alternância, assumida pela LEdoC da UFF, fomenta diferentes perspectivas dos movimentos de (re)descoberta no (re)desenhar das lutas emancipatórias nas esferas públicas, sociais, epistêmicas e acadêmicas em defesa das escolas do campo. 


\section{REFERÊNCIAS}

ANDRADE, F. M. R.; NOGUEIRA, L. P. M.; NEVES, L. C.; RODRIGUES, M. P. M. Educação do Campo em giro decolonial: a experiência do Tempo Comunidade na Universidade Federal Fluminense (UFF). Revista Brasileira de Educação Do Campo. n. 4, e7178, 2019a.

ANDRADE, F. M. R; NOGUEIRA, L. P. M.; RODRIGUES, M. P. M. Tempo Comunidade - espaçotempo potencializador de experiências na formação de educadores do campo. In: COSTA, Alvaro Daniel (Org.). Cultura, cidadania e políticas públicas 2. Ponta Grossa (PR): Atena Editora, p. 154-163, $2019 \mathrm{~b}$.

ANDRADE, F. M. R.; CORRÊA, M. S. T. Pedagogias e mulheres em movimentos: enfrentamentos à violência doméstica. 1. ed. - Curitiba: Appris, 2020.

ANDRADE, F. M. R.; RODRIGUES, M. P. M. Escolas do Campo e Infraestrutura: aspectos legais, precarização e fechamento. Educação em Revista. v. 36, Belo Horizonte, 2020.

ARROYO, M. G. Outros Sujeitos, Outras Pedagogias. 2.ed. - Petrópolis, RJ: Vozes, 2014.

ARROYO, M. G. Formação de Educadores do Campo. In: CALDART, R. S. et al. (Org.). Dicionário da Educação do Campo. Rio de Janeiro, São Paulo: Escola politécnica de Saúde Joaquim Venâncio, Expressão Popular, p. 361-367, 2012. ARROYO, M. G.; CALDART, R. S.; MOLINA, M.C. Por uma educação do campo. Petrópolis: Vozes, 2004.

BICALHO, R. A formação do educador de jovens e adultos e os movimentos sociais do campo. Revista Educação Popular, Uberlândia, v. 17, n. 2, maio/ago., 2018, p. 21-34.

BICALHO, R.; BEZERRA, S. F. A influência histórica dos movimentos sociais em favor das políticas públicas de educação do campo. Cadernos CIMEAC, [S.I.], v. 8, n. 1, jul., p. 94-115, 2018.

BRASIL. Lei n. 12.960, de 27 de março de 2014. Altera a Lei no 9.394, de 20 de dezembro de 1996, que estabelece as Diretrizes e Bases da Educação Nacional, para fazer constar a exigência de manifestação de órgão normativo do sistema de ensino para o fechamento de escolas do campo, indígenas e quilombolas. Disponível em: http://www.planalto.gov.br/CCIVIL_03/_Ato20112014/2014/Lei/L12960.htm. Acesso em: 20 nov. 2020.

BRASIL. Lei n. 9.394, de 20 de dezembro de 1996. (1996, 23 de dezembro). Estabelece as Diretrizes e Bases da Educação Nacional. Disponível em: http://www.senado.gov.br/sf/legislacao. Acesso em: 13 out. de 2020. 
BRASIL. Presidência da República. Decreto no 7.352, de 4 de novembro de 2010. Dispõe sobre a política de educação do campo e o Programa Nacional de Educação na Reforma Agrária - PRONERA. Disponível em: http://www.planalto.gov.br/ccivil_03/_ ato20072010/2010/decreto/d7352.htm. Acesso em: 13 out. 2020.

CALDART, R. S. Educação do campo. In: CALDART, R. S. et al. (Org.). Dicionário da Educação do Campo. Rio de Janeiro, São Paulo: Escola politécnica de Saúde Joaquim Venâncio, Expressão Popular, p. 259-267, 2012. CALDART, R. S. Educação do Campo: notas para uma análise de percurso. Trab. Educ. Saúde, Rio de Janeiro, v. 7 n. 1, p.35-64, 2009.

CALDART, R. S. O MST e a escola: concepção de educação e matriz formativa. CALDART, R. S. (Org.). Caminhos para a transformação da escola: reflexões desde a prática da licenciatura em Educação do Campo. 1. ed. São Paulo: Expressão Popular, p. 63-83, 2010.

CALDART, R. S. Pedagogia do Movimento Sem Terra. 3.ed. - São Paulo: Expressão Popular, 2004.

CALDART, R. S. Por Uma Educação do Campo: traços de uma identidade em construção. In: KOLLING, Edgar Jorge et al. (Orgs.). Educação do Campo: Identidade e Políticas Públicas. - Brasília, DF: Articulação Nacional por uma Educação do Campo, p. 147-158, 2002.

CNE - Conselho Nacional de Educação. Proposta de regulamentação da Pedagogia da Alternância. Brasília, 2020. Disponível em: http://portal.mec.gov.br/docman/junho-2020-pdf/146891-texto-referenciapedagogia-da-alternancia/file. Acesso em: 26 ago. 2020.

COSTA, M. C. V. A caminho de uma pesquisa-ação crítica. Educação e Realidade. V.16 no 2, jul. dez, p. 46-52, 1991.

CUNHA, L. A. Movimentos Sociais, Sindicais e Acadêmicos. In Educação, Estado e Democracia no Brasil. 4aㅡ ed. - São Paulo: Cortez; Niterói, RJ: Editora da Universidade Federal Fluminense; Brasília, DF: FLACSO do Brasil, Biblioteca da educação. Série 1. Escola; v. 17, cap. 2, p. 57-72, 2001.

DEMO, P. Metodologia cientifica em ciências sociais. - 3. ed. rev. ampl. São Paulo: Atlas, 1995.

FREIRE, P. Educação como prática da liberdade. Rio de Janeiro: Paz e Terra, 1967.

FREIRE, P. Pedagogia da Indignação: cartas pedagógicas e outros escritos. São Paulo: UNESP, 2000. 
FREIRE, P. Pedagogia do oprimido. Rio de Janeiro: Paz e Terra, 2005.

FRIGOTTO, G. et al. Introdução. In: FRIGOTTO, G. et al. (Org.). História, Natureza, Trabalho e Educação. 1a ed. São Paulo: Expressão Popular, p.11$22,2020$.

INEP - Instituto Nacional de Estudos e Pesquisas Educacionais Anísio Teixeira. Catálogo de Escolas. Disponível em: https://www.gov.br/inep/pt-br/acesso-ainformacao/dados-abertos/inep-data/catalogo-de-escolas. Acesso em: 5 mar. 2020.

MARX, K.; ENGELS, F. Burgueses e Proletários (1848). In: FRIGOTTO, G. et al. (Org.). História, Natureza, Trabalho e Educação. $1^{\text {a }}$ ed. São Paulo: Expressão Popular, p.133-146, 2020.

MOLINA, M. C.; SÁ, L. M. Escola do Campo. In: CALDART, R. S. et al. (Orgs.). Dicionário da Educação do Campo. Rio de Janeiro, São Paulo: Escola politécnica de Saúde Joaquim Venâncio, Expressão Popular, 2012 Dicionário da Educação do Campo, p. 326-332, 2012.

MST - Movimento dos Trabalhadores Rurais Sem Terra. Caderno de Educação n. 13: Dossiê MST escola: documentos e estudos 1990-2001. São Paulo, SP: Setor de Educação, 2005.

NEVES, L. C. et al., Memória social e resistência: organização comunitária contra o fechamento da escola Alice do Amaral Peixoto. In. COSTA, Álvaro Daniel (org.). Cultura, cidadania e políticas públicas. v. 4. Ponta Grossa (PR): Atena Editora, p. 130-137, 2019.

PORTO-GONÇALVES, C. W. Apresentação da edição em português. In: Lander, Edgardo (Org.). Colonialidade do poder, eurocentrismo e América Latina. A colonialidade do saber: eurocentrismo e ciências sociais. Perspectivas LatinoAmericana. Colección Sur Sur. CLACSO, Ciudad Autónoma de Buenos Aires, p. 3-5, 2005.

RIBEIRO, M. Movimento Camponês Trabalho e Educação: liberdade, autonomia, emancipação: princípios/fins da formação humana. 2.ed. - São Paulo: Expressão Popular, 2013.

RODRIGUES, M. P. M. A precarização enquanto estratégia de fechamento de escolas do campo: uma análise da infraestrutura de três escolas do Noroeste Fluminense. Trabalho de Conclusão de Curso (Licenciatura Interdisciplinar em Educação do Campo) - Universidade Federal Fluminense, Santo Antônio de Pádua - RJ, 2019.

ROSSATO, M.; Martínez, A. M. A metodologia construtiva-interpretativa como expressão da Epistemologia Qualitativa na pesquisa sobre o desenvolvimento 
da subjetividade. Investigação Qualitativa em Educação, v. 1, p. 343-352, 2017.

SADER, E. Quando Novos Personagens Entraram em Cena. Experiências, falas e Lutas dos Trabalhadores da Grande São Paulo: 1970-80. Rio de Janeiro: Paz e Terra, 1988.

SCHMITZ, M. T.; CASTANHA, A. P. Fechamento de escolas do campo: o caso da Escola Estadual do Campo Canoas - Cruzeiro do Iguaçu - PR. Imagens da Educação, v. 7, n. 1, p. 38-48, 2017.

WALSH, C. Pedagogías decoloniales: prácticas insurgentes de resistir, (re) existir y (re) vivir. Abya Yala, 2013.

Recebido em: 22/04/2021

Aprovado em: 22/09/2021 